\title{
A Sociolinguistic Study of Language and Gender in Desperate Housewives
}

\author{
Jie Li \\ Foreign Languages College, Inner Mongolia University, W. Hohhot, 010021, China
}

\begin{abstract}
Since language is used as a tool for human communication, it is inevitably featured by gender. For quite a long time, language and gender study has been a heated issue in sociolinguistics and pragmatics. Former studies focus on linguistic levels such as phonology, grammar, syntax and gender differences. However, few of them are conducted in specific contexts. With the development of society, language and gender study in a certain context deserves to be conducted. Under such background, the proposed research examines language and gender in Desperate Housewives based on conversational analysis as its theoretical framework. It randomly selects each episode from all eight seasons as data source and adopts quantitative and qualitative analysis, comparison and contrast method. The study mainly concentrates on differences in the amount of talk, the amount of turns and distribution of them. Its findings are as follows. In terms of the amount of talk, men use more words to compose more sentences. In other words, they are much more talkative than women. In the aspect of the amount of turns, men are inclined to take the turn floor for a longer time. In a word, the proposed research, though has some limitations, is of theoretical and practical significance.
\end{abstract}

Index Terms—sociolinguistics, language and gender, Desperate Housewives

\section{INTRODUCTION}

As a branch of macro-linguistics, sociolinguistics has come into being since the 1960s in America. Since then, it has involved many significant research topics, among which is language and gender. As Wardhaugh (2000) states, "A major topic in sociolinguistics is the connection, if any, between the structures, vocabularies, and ways of using particular languages and the social roles of the men and women who speak these languages" (P. 309). The topic has evoked heated discussion. And a large amount of scholars at home and abroad have contributed a lot to its study, such as Lakoff, Trudgill, Zimmerman, West, Thorne, Henley and Bolinger abroad and Chen Jianmin, Du Wenli, Yang Yonglin, Zhao Ronghui, and so on.

Generally speaking, most of the studies on language and gender focus on the following three aspects: gender differences in language; sexism in language; causes for gender differences and sexism in language. Few of them are conducted in specific contexts. Among these contexts, Desperate Housewives, created by Marc Cherry, enjoys the highest popularity. The show contains a large number of authentic and daily conversations between males and females, which can serve as a typical and representative data source of language and gender study. Besides, former studies are carried out from the perspective of pragmatics and stylistics, but few from the perspective of sociolinguistics. The proposed research therefore will compensate for such insufficiency in the hope of obtaining some useful insights into and adding fresh blood to language and gender study.

In this study, Conversational Analysis (CA) functions as the theoretical framework for it is quite suitable for the study of conversation and gender. Based on former studies on language and gender and CA, the author originally divides this analysis into two main parts: the analysis of the amount of talk and the analysis of turn-taking.

\section{RESEARCh DESIGN}

\section{A. Research Questions:}

With research background and the thesis statement in mind, we can now put forward the following two questions:

Research question one: What are the differences between men and women in the amount of talk?

Research question two: Whether there are differences in the amount of turns and distribution of them?

\section{B. Data Source and Data Collection}

The data employed in this proposed research is exclusively from the well-known American TV series, Desperate Housewives. The author randomly chooses one episode of each season as the subject of study not only because it is popular with viewers all over the world, but also because it contains many daily conversations among men and women. This makes it suitable for the study of language and gender.

In terms of data collection, the study randomly selects one episode of each season for the sake of scientific and objective purpose. In order to gain the exact and proper data, the author first downloads the 8 episodes of the eight seasons from the Internet. Then they are played over and over again via the media player. Meanwhile, relevant speeches and conversations between men and women are written down on paper for later observation and analysis. After all these, 
the data on language and gender in this series goes through the analysis procedures mentioned in III for a scientific and systematic study.

\section{Research Methodology}

In terms of research methodology, it refers to the combination of research methods. The methods used in the proposed research can be classified as a case study with the combination of quantitative and qualitative analysis. The quantitative approach is to use tables and figures to show the differences in the amount of talk and turns. The qualitative approach is to give a systematic description of the data.

The exact analysis procedure proceeds in the following way. Since the conversational analysis serves as the theoretical framework, a thorough analysis of language and gender in Desperate Housewives will be conducted from two main aspects: the analysis of the amount of talk and the analysis of turn-taking. To be specific, the analysis of the amount of talk will concentrate on the amount of words and sentences; the analysis of turn-taking will focus on the amount of turns and the distribution of them. In the process of analysis, statistic exploration will be demonstrated in tables. Following it, qualitative analysis will be made to fully study gender differences in these two aspects in this show. Meanwhile, comparison and contrast method is employed so as to make a scientific and systematic study. After the detailed analysis, the author arrives at a conclusion of the proposed research by clarifying major findings, limitations and suggestions for further studies.

\section{The Studies OF LANGUAGE AND GeNDER}

Since the proposed research is intended to analyze language and gender in Desperate Housewives from the perspective of sociolinguistics, it is necessary to have a brief review of studies on language and gender and Desperate Housewives respectively.

\section{A. The Studies of Language and Gender Abroad}

The earliest research about language and gender can be traced back to as early as ancient Greek. At that time, many dramas witnessed gender differences in language. However, it was not until the early $20^{\text {th }}$ century that language and gender attracted anthropologists' and linguists' attention.

Though there is a trend to study language and gender, it has not become an independent linguistic topic until the 1960s, when feminist movement appeared and sociolinguistics advanced. In the 1770s, such well-known linguists as Lakoff, Trudgill, Zimmerman, West, Thorne and Henley made a great contribution to the study by exploring the social roots of gender differences in language. Gradually, researches and studies began to flourish. In the early 1980s, Bolinger and other linguists thought of gender differences in language as a kind of sexism.

In recent years, conversational analysis serves as a new and important approach in the study of language and gender. It is regarded as an influential branch in the modern gender language field for it has broadened its scope into a variety of formal and informal settings, and connected gender with conversational features, such as the amount of talk and turns.

Generally speaking, the studies abroad emphasize on three aspects: gender differences in language; sexism in language; causes for gender differences and sexism in language. Based on the studies abroad, the proposed research adopts the conversational approach and tries to make a deep analysis of language and gender in Desperate Housewives, in the hope of adding fresh blood to relevant studies.

\section{B. The Studies of Language and Gender at Home}

The relevant researches on language and gender in China began in the late 1970s and early 1980s. In the general, the domestic researches fall into four aspects: introduction to western theories; sexism reflected in language; gender differences in language; gender differences in communication.

The first is introduction to western theories including translation of theories, theory summaries and book comments like Yang Yonglin (1991)'s and Zhao Ronghui (1999)'s summaries of the studies abroad. The second is sexism reflected in language, especially the one towards women. Studies by Du Wenli (1993) and Chen Jianmin (1999) are of significance in this regard. The third is gender differences in language. Most analysis materials are English. The most representative works are from Yang Yonglin (1993). They show gender differences in phonological, lexical and syntactical levels. The last is gender differences in communication. Such study is a hot issue which ranges from conversational structures and strategies to conversational styles.

In spite of the above mentioned achievements, there are also limitations. Most of the studies focus on linguistic levels. As a result, discussions on conversational levels are insufficient. Furthermore, a large number of studies are decontextualized. Therefore, the proposed research intends to deeply analyze language and gender in an actual context, especially the conversational structures in Desperate Housewives.

\section{The Studies of Desperate Housewives}

Desperate Housewives, created by Marc Cherry, is an American TV series. Since its premiere on American Broadcasting Company on October 3, 2004, it has been translated into many languages, and broadcast in more than 130 countries all over the world.

The show is set in the street of Wisteria Lane in the fictional American town of Fairview. It is composed of eight 
seasons, each season having a new housewife join in. It mainly tells the unknown life of four housewives from the perspective of Mary Alice who commits suicide with a gun in her house. The four heroines, Susan, lynette, Bree and Gabrielle, are distinct housewives. Faced up with secrets, crimes hidden behind their neighborhood, they finally get through family and neighbor struggles.

Due to its popularity, Desperate Housewives has become a hot research data. However, former studies are mostly from pragmatics and stylistics and few from sociolinguistics. Researchers intended to investigate how pragmatic principles are observed or violated in conversations. Additionally, the show contains many daily conversations among women and men. Thus, it is quite suitable for the study of language and gender.

\section{Analysis of Language And Gender in Desperate Housewives}

The following is a thorough and detailed analysis of language and gender in Desperate Housewives. We mainly focus on the amount of talk and turns, and the distribution of them.

\section{A. Analysis of the Amount of Talk}

In the general, amount of talk means how much a speaker speaks in a conversation. Its study concerning gender is to study which gender is more talkative. As is widely acknowledged, women are more talkative. A large amount of former studies have proven this belief. However, recent studies challenge it. Mary M. Talbot (1998), in her book Language and Gender: An Introduction, made the conclusion that men are more talkative under some occasions. Many other scholars further deepened the study and arrived at the same conclusion.

Then, how about the result in Desperate Housewives? Can the results of previous studies applied to the TV series? The author will investigate it in the following paragraph. The author will employ the common method which compares the total amount of words and sentences, and the average amount of them of both genders.

The table presents the findings of the amount of words and sentences in the eight episodes extracted from the American TV series Desperate Housewives.

TABLE 1

TABLE OF AMOUNT OF TALK

\begin{tabular}{|c|c|c|c|c|c|}
\hline Gender $\quad$ Items & Word amount & Sentence amount & $\begin{array}{l}\text { Average sentence } \\
\text { length }\end{array}$ & Word ratio & Sentence ratio \\
\hline Males & 2107 & 274 & 7.69 & $69.2 \%$ & $61.2 \%$ \\
\hline Females & 938 & 174 & 5.39 & $30.8 \%$ & $38.8 \%$ \\
\hline Total & 3045 & 448 & 13.08 & $100 \%$ & $100 \%$ \\
\hline
\end{tabular}

From the table above, it can be seen that among the 3045 words, there are 2107 used by males, accounting for $69.2 \%$, while 928 used by females, accounting for 30.8\%. In terms of the amount of sentences, males use the 2107 words to compose 274 sentences, taking up $61.2 \%$ of the total number. However, females only compose 174 sentences, taking up $38.8 \%$ of the total number. This clearly manifests that men speak far more than women in conversations. This finding is in accordance with that of Mary M. Talbot (1998) that men, in a conversation between both genders, are relatively more talkative.

The conversation below is extracted from the first episode of the eighth season. It happens between the perfect housewife Bree and the priest Reverend Sykes. After Bree's boyfriend, Keith, left him, she invited Reverend Sykes to her house to have a talk, which, she thought, may help her feel relieved. The analysis can help us fully understand the conclusion above.

Example one:

Reverend Sykes: Thank you, Bree. It always brightens my day when you invite me to visit.

Bree: Well, Reverend Sykes, I very much enjoy your company.

Reverend Sykes: As I do yours. (Silence for three seconds) So... have you killed someone?

Bree: Excuse me?

Reverend Sykes: I've always found the treats you prepare for my visits are a reliable indicator of your level of spiritual turmoil. The more exquisite the baked goods, the more anguished your soul. This...is a hazelnut chocolate chip scone with currants. So I ask again-have you killed someone?

Bree: No. It's just...Lately, I feel like Job. You know, Job, from the old testament?

Reverend Sykes: I'm familiar with the book. Thank you. Why do you think you're Job?

Bree: I just feel that God has taken everything away from me. I lost my business, my children never call me, and...my boyfriend Keith has left me.

Reverend Sykes: Well, it's not exactly body boils and dead camels, but I understand what you're saying. When I complained after I was not accepted into Yale Divinity School, my father had no sympathy. Instead he drove me from our lovely home in Connecticut to a dangerous section of the Bronx and forced me to hand out blankets to the homeless.

Bree: I see. That's the reason you're always been so sensitive to the plight of the poor.

Reverend Sykes: Perhaps. It's certainly the reason my father was buried in a sport jacket he detested. The point is, looking at what has been taken away from us is a bad way to go through life. Looking for what we can give to others is far better. 
In this short conversation between Bree and Reverend Sykes, there are 255 words all together, composing 27 sentences. Among the 255 words, the man used 188, whose word ratio reaches as highly as $73.7 \%$, far more than that of the women, only $26.3 \%$. In terms of the sentence number, there are 18 composed by the man, occupying $66.7 \%$ of the total number, while there are only 9 made by the woman, occupying 33.3\%. It is clearly shown that Reverend Sykes spoke far more than Bree. He appeared to be much more talkative in their short conversation.

Example two:

Susan: I wouldn't eat that if I were you.

Mike: Why?

Susan: I made it. Trust me.

Mike: (He is eating the food)

Susan: Hey. Do you have a death wish?

Mike: No, I just refused to believe that anybody can screw up macaroni and cheese. (Mike is eating the food)

Mike: Oh, my god. How did you...? It tastes like it's burnt and undercooked.

Susan: Yeah. I get that a lot. Here you go.

Mike: Thanks. I'm Mike Delfino. I just started renting the Sim's house next door.

Susan: Susan Mayer. I live across the street.

Mike: Mrs Huber told me about you, said you illustrate children's books.

Susan: Yeah. I'm very big with the under-five set. What do you do?

Mike: Plumber. So if you ever have a clog... or something.

(They smile to each other)

The conversation above is extracted from the first episode of the first season. It happens between Susan and Mike. After Mary Alice's funeral, the neighbors came to her house to pay their respect. There, Susan and Mike met each other and began their first conversation. In this short conversation, there are 12 sentences made up of 109 words. Among all these 12 sentences, the man and the woman take up 6 respectively. However, the man used 61 words, whose word ratio reaches $56 \%$, far more than that of the woman, only $44 \%$. Obviously, the man spoke more than the woman.

Various such examples in Desperate Housewives can be easily found. They all show the differences in the amount of talk in conversations between males and females.

\section{B. Analysis of Turn-taking}

Turn-taking is the fundamental rule to guarantee the smooth transition of a conversation. According to Levinson (2001), it means one participant A to another participant B; another participant B begins to talk and then stops. Its study concerning gender is to study which gender initiates or offers the turn, and which gender takes the turn floor for a longer time. In the proposed research, we focus on the latter.

It is agreed that men are inclined to take the turn for a longer time in a conversation between males and females. Is it true in Desperate Housewives. In the following part, we will examine it.

In Desperate Housewives, we see differences in the time of both genders taking the turn floor. The following table shows the amount and distribution of turns in conversations between males and females.

TABLE 2:

TABLE OF TURNS

\begin{tabular}{|l|l|l|l|l|}
\hline Gender & Turn number & Word number & Average turn length & Ratio \\
\hline Males & & & & $52.3 \%$ \\
\hline Females & 126 & 2107 & 16.72 & $47.7 \%$ \\
\hline Total & 115 & 938 & 8.16 & 12.63 \\
\hline
\end{tabular}

From the table, we can clearly see that men's turns reach as highly as 126 in all the eight episodes of the eight seasons, which take up 52.3\% of all the turns. Compared with men's turns, women's turns occupy $47.7 \%$ of all the turns. In terms of average turn length, there is an obvious difference that a gap of 8.56 words between male talks and female talks. Thus, females speak far less than males in a turn. This finding is in accordance with that of some scholars that men, in a conversation between both genders, take the turn floor for a longer time.

The following is an example of conversation between two genders in Desperate Housewives. The analysis will enable us to have a better understanding of the amount of turns and distribution of them.

It is extracted from the first episode of the first season. The conversation happens between a couple, Bree and Rex when Rex is in hospital because of a car accident. Bree is a perfectionist while Rex is sick of her perfectionism.

Rex: I can't believe you tried to kill me.

Bree: Yes, well I feel badly about that. I told you Mrs. Huber came over and I got distracted. It was a mistake.

Rex: Since when do you make mistakes?

Bree: What does that mean?

Rex: It means I'm sick of you being so damn perfect all the time. I'm sick of the bizarre way your hair doesn't move. I'm sick of you making bed in the morning before I've used the bathroom. You're this plastic suburban housewife with her pearl and spatula, who says things like "We owe the Hendersons a dinner." Where's the woman I fell in love 
with? ...Who used to burn toast and drink milk out of the carton? And laugh. I need her. Not this cold, perfect thing you've become.

Bree: These need water. (Then she walks out of the room.)

In this short conversation, there are all together 6 turns, each gender occupying 3. Even though, the hero, Rex, say more words than the heroine, Bree. In other words, He takes the turn floor for a longer time. This is also true in the above two examples.

A variety of examples of differences in the amount of turns and distribution of them can be found in this TV series. Turns in conversation are basic units and they are worthy of being studied in a specific context.

To sum up, there are differences in the amount of talk and turns, and the distribution of them. It is safe to say that on some occasions men are more talkative and tend to take the turn floor for a longer time than women.

\section{CONCLUSIONS}

\section{A. Major Findings}

The proposed research studies language and gender in the American TV series Desperate Housewives. Eight randomly chosen episodes from the eight seasons serve as the data resource. Based on former studies, this paper is conducted under the theoretical framework of conversational analysis. Exactly speaking, analysis of language and gender in this paper involves two main parts: the analysis of the amount of talk; the analysis of turn-taking. It has made a thorough study of these two aspects in the specific context. Quantitative and qualitative examination, together with comparison and contrast method shows the differences in the amount of talk, turns and distribution of them. The findings of this paper add fresh blood to language and gender study.

In terms of the amount of talk, the proposed research finds that men occupy a higher rate. Their word and sentence amounts take up $69.2 \%$ and $61.2 \%$ of the total in all eight episodes respectively, while women's only $30.8 \%$ and $38.8 \%$ respectively. The statistics show the fact that men are more talkative than women on some occasions.

Analysis of turn-taking concerning gender in Desperate Housewives mainly centers on the amount of turns and distribution of them. Among all the turns in the eight episodes, males occupy $52.3 \%$ while females $47.7 \%$. Though the gap is small, it also demonstrates that men are inclined to take the turn floor for a longer time when they have a conversation with women.

\section{B. Limitations}

This proposed research has been finished with several limitations. First and foremost, the proposed research is conducted in an English context. Its data is only collected from one of the well-known American TV series. Others are supposed to be taken into consideration. Though the author has closely examined one episode of each season, a much larger sample is needed so as to add color to present study.

Besides, the proposed research on language and gender mainly refers to conversations between males and females, namely, the mixed group. Therefore, the results may not suitable for other gender groups, such as female-female and male-male groups. It is noticed that gender group is also a variable that cannot afford to be ignored for different gender groups have different indications for different topics.

Last but not least, the proposed research only focuses on the most typical aspects in Desperate Housewives. In the analysis of the amount of talk, it only studies the amount of words and sentences. However, there are other aspects worthy of study, such as the amount of adjacency pairs. Likely, in the analysis of turn-taking, this study mainly concentrates on the amount and distribution of turns while other aspects like interruption and overlap are ignored. In addition, language and gender study from the perspective of conversational strategies including silence, minimal response, and styles including politeness and directness is missing. However, it may involve a large amount of study, which may surpass the space. The proposed research therefore gives up the study of those aspects.

All these need to be improved in further studies.

\section{ACKNOWLEDGEMENT}

I would like to give my sincere thanks to several people for their invaluable help in my academic studies over the past one year.

First and foremost, my heartfelt gratitude goes to my supervisor, Professor Duan Manfu for his kindness, encouragement, instructive suggestions and excellent guidance in my studies in Inner Mongolia University. Without his great help in various ways, this paper would have never been possible. What's more, his rigorous spirit will benefit me in all my life.

My thanks should also be extended to other professors, like Pro. Li, Pro. Liu, Pro. Zheng, Pro. Wei, and Pro. Bai. For the past one year, they have exerted great efforts to help me gain a full understanding of my academic areas.

My friend Qin Liting has shared her constructive ideas with me. I appreciate her enlightening suggestions and back-breaking jobs very much.

Last but not least, my parents have shown unremitting support and encouragement over the years by shouldering my tuition fees and living costs. To them, I owe a special gratitude. 


\section{REFERENCES}

[1] Chen Jianmin. (1999). The Language and Society of China. Guang Zhou: Guang Zhou Education Press.

[2] Du Wenli. (1993). On Gender Discrimination in English. Shan Dong Foreign Language Teaching Journal, 2, 15-17.

[3] Levinson, S. (2001). Pragmatics. Cambridge: Cambridge University Press.

[4] Liu Hong. (2004). Analysis of Conversational Structure. Beijing: Peking University Press.

[5] Talbot, M. M. (1998). Language and Gender: An Introduction. Cambridge: Polity Press.

[6] Wardhaugh, R. (2000). An Introduction to Sociolinguistics ( $3^{\text {rd }}$ edtion). Beijing: Foreign Language Teaching and Research Press.

[7] Yang Yonglin. (1991). A Review of Gender Differences in Modern English. Shan Dong Foreign Language Teaching Journal, 2 , $1-12$.

[8] Zhao Ronghui. (1999). A Review of Language and Gender Study. Foreign Language Research, 3, 1-5.

[9] Zhang, T. G. \& Hao, S. Z. (2008). Theories and Application of Sociolinguistic Research. Beijing: Peking University Press.

Jie Li was born in Tong Liao, Inner Mongolia, China in 1991. She received her MA degree in English Linguistics from Inner Mongolia University for Nationalities, China in 2012.

She is currently a post-graduate in Foreign Languages College, Inner Mongolia University, China. Her research interest includes sociolinguistics. 